\title{
Current State-of-Art and New Trends on Lipid Nanoparticles (SLN and NLC) for Oral Drug Delivery
}

\author{
Patrícia Severino, ${ }^{1,2}$ Tatiana Andreani, ${ }^{2,3,4}$ Ana Sofia Macedo, ${ }^{2}$ Joana F. Fangueiro, ${ }^{2}$ \\ Maria Helena A. Santana, ${ }^{1}$ Amélia M. Silva, ${ }^{3,4}$ and Eliana B. Souto ${ }^{2,5}$ \\ ${ }^{1}$ Department of Biotechnological Processes, School of Chemical Engineering, State University of Campinas (UNICAMP), \\ 13083-970 Campinas, SP, Brazil \\ ${ }_{2}^{2}$ Faculty of Health Sciences, Fernando Pessoa University (FCS-UFP), Rua Carlos da Maia, 296, 4200-150 Porto, Portugal \\ ${ }^{3}$ Department of Biology and Environment, University of Trás-os Montes e Alto Douro, 5001-801 Vila Real, Portugal \\ ${ }^{4}$ Centre for Research and Technology of Agro-Environmental and Biological Sciences, 5001-801 Vila Real, Portugal \\ ${ }^{5}$ Institute of Biotechnology and Bioengineering, Centre of Genomics and Biotechnology, University of Trás-os-Montes and Alto Douro \\ (CGB-UTAD/IBB), P.O. Box 1013, 5001-801 Vila Real, Portugal
}

Correspondence should be addressed to Eliana B.Souto, eliana@ufp.edu.pt

Received 19 July 2011; Revised 5 October 2011; Accepted 5 October 2011

Academic Editor: Rajesh Patil

Copyright ( $) 2012$ Patrícia Severino et al. This is an open access article distributed under the Creative Commons Attribution License, which permits unrestricted use, distribution, and reproduction in any medium, provided the original work is properly cited.

Lipids and lipid nanoparticles are extensively employed as oral-delivery systems for drugs and other active ingredients. These have been exploited for many features in the field of pharmaceutical technology. Lipids usually enhance drug absorption in the gastrointestinal tract (GIT), and when formulated as nanoparticles, these molecules improve mucosal adhesion due to small particle size and increasing their GIT residence time. In addition, lipid nanoparticles may also protect the loaded drugs from chemical and enzymatic degradation and gradually release drug molecules from the lipid matrix into blood, resulting in improved therapeutic profiles compared to free drug. Therefore, due to their physiological and biodegradable properties, lipid molecules may decrease adverse side effects and chronic toxicity of the drug-delivery systems when compared to other of polymeric nature. This paper highlights the importance of lipid nanoparticles to modify the release profile and the pharmacokinetic parameters of drugs when administrated through oral route.

\section{Introduction}

The use of lipid particles in pharmaceutical technology has been reported for several years. The first approach of using lipid microparticles was described by Eldem et al. [1], reporting the production by high-speed stirring of a melted lipid phase in a hot surfactant solution obtaining an emulsion. Solid microparticles are formed when this emulsion is cooled to room temperature, and the lipid recrystallizes. The obtained products were called "lipid nanopellets", and they have been developed for oral administration [2]. Lipospheres were described by Domb applying a sonication process [3-5]. To overcome the drawbacks associated to the traditional colloidal systems [6], such as emulsions [7], liposomes [8], and polymeric nanoparticles [9], solid lipid nanoparticles (SLN) $[10,11]$ have been developed for similar purposes [12].
SLN are biocompatible and biodegradable and have been used for controlled drug delivery and specific targeting. These colloidal carriers consist of a lipid matrix that should be solid at both room and body temperatures, having a mean particle size between $50 \mathrm{~nm}$ and $1000 \mathrm{~nm}[13,14]$.

A clear advantage of the use of lipid particles as drugcarrier systems is the fact that the matrix is composed of physiological components, that is, excipients with generally recognized as safe (GRAS) status for oral and topical administration, which decreases the cytotoxicity. SLN have been already tested as site-specific carriers particularly for drugs that have a relatively fast metabolism and are quickly eliminated from the blood, that is, peptides and proteins [15].

The cytotoxicity of SLN can be attributed to nonionic emulsifiers and preservative compounds which are used in 
the production of these systems [16]. SLN prepared up to concentrations of $2.5 \%$ lipid do not exhibit any cytotoxic effects in vitro [17]. Even concentrations higher than $10 \%$ of lipid have been shown a viability of $80 \%$ in culture of human granulocytes [18]. In contrast, some polymeric nanoparticles showed complete cell death at concentrations of $0.5 \%$. In addition, a high loading capacity for a broad range of drugs can be achieved, especially if they have lipophilic properties $[12,19]$.

Due to their physiological and biodegradable properties, SLN have been tested for several administration routes [20, $21]$, including the oral $[22,23]$ and peroral $[24,25]$ routes.

SLN can be obtained by exchanging the liquid lipid (oil) of the o/w nanoemulsions by a solid lipid [19]. In general, a solid core offers many advantages in comparison to a liquid core [26]. Emulsions and liposomes usually show lack of protection of encapsulated drugs, and drug release as a burst (emulsions) or noncontrolled (from liposomes). SLN possess a solid lipid matrix identical to polymeric nanoparticles. In addition, SLN are of low cost [27], the excipients and production lines are relatively cheap, and the production costs are not much higher than those established for the production of parenteral emulsions [28].

At the turn of the millennium, modifications of SLN, the so-called nanostructured lipid carriers (NLCs), have been introduced to the literature, and these NLC represent nowadays the second generation of lipid nanoparticles. These carrier systems overcome observed limitations of conventional SLN [29]. The main difference between SLN and NLC is the fact that the concept of these latter is performed by nanostructuring the lipid matrix, in order to increase the drug loading and to prevent its leakage, giving more flexibility for modulation of drug release. This approach is achieved by mixing solid lipids with liquid lipids in NLC instead of highly purified lipids with relatively similar molecules in SLN. This mixture has to be solid at least at $40^{\circ} \mathrm{C}$. The result is a less-ordered lipid matrix with many imperfections, which can accommodate a higher amount of drug [11].

\section{Role of Lipids in Oral Delivery}

A limiting factor for in vivo performance of poorly watersoluble drugs for oral administration is their resistance of being wetted and dissolved into the fluid in the GIT (apart from potential drug degradation in the gut). Thus, the increase in the dissolution rate of poorly water-soluble drugs is relevant for optimizing bioavailability. Over the last 10 years, poorly water-soluble compounds are formulated in lipid nanoparticles for drug administration [30]. The features of lipid nanoparticles for oral and peroral delivery are related with their adhesive properties. Once adhered to the GIT wall, these particles are able to release the drug exactly where it should be absorbed. In addition, the lipids are known to have absorption-promoting properties not only for lipophilic drugs, such as Vitamin E, repaglinide [22], and puerarin [23].

Hydrophilic drugs can also be incorporated in SLN; nevertheless, the affinity between the drug and the lipid needs to be analysed. Therefore, loading hydrophilic drugs in SLN is a challenge due to the tendency of partitioning the encapsulated molecules in the water during the production process of nanoparticles [31]. Successful examples are zidovudine [31], insulin [32], tretinoin [33], and diminazene [34]. There are even differences in the lipid absorption enhancement depending on the structure of the lipids. For example, medium-chain triglycerides (MCT) lipids are more effective than long-chain triglycerides (LCT) [35]. Basically, the body is taking up the lipid and the solubilized drug at the same time. It can be considered as a kind of "Trojan horse" effect $[36,37]$.

Oral administration of SLN is possible as aqueous dispersion [38] or alternatively transformed into a traditional dosage forms such as tablets, pellets, capsules, or powders in sachets $[25,39]$. For this route, all the lipids and surfactants used in traditional dosage forms can be exploited. In addition, all compounds of GRAS status or accepted GRAS status can be employed as well as from the food industry [40]. Since the stomach acidic environment and high ionic strength favour the particle aggregation, aqueous dispersions of lipid nanoparticles might not be suitable to be administered as dosage form. In addition, the presence of food will also have a high impact on their performance [41].

The packing of SLN in a sachet for redispersion in water or juice prior to administration will allow an individual dosing by volume of the reconstituted SLN. For the production of tablets, the aqueous SLN dispersions can be used instead of a granulation fluid in the granulation process. Alternatively, SLN can be transferred to a powder (by spray-drying or lyophilization) and added to the tabletting powder mixture. In both cases, it is beneficial to have a higher solid content to avoid the need of having to remove too much water. For cost reasons, spray drying might be the preferred method for transforming SLN dispersions into powders, with the previous addition of a protectant [42].

For the production of pellets, the SLN dispersion can be used as a wetting agent in the extrusion process. SLN powders can also be used for the filling of hard gelatine capsules. Alternatively, SLN can be produced directly in liquid PEG 600 and put into soft gelatine capsules. Advantages of the use of SLN for oral and peroral administration are the possibility of drug protection from hydrolysis, as well as the possible increase of drug bioavailability. Prolonged plasma levels has also been postulated due to a controlled, optimized released [22] in combination with general adhesive properties of small particles [43]. The advantage of colloidal drug carriers described above is that they are generally linked to their size in the submicron range. Therefore, the preservation of particle size of colloidal carrier systems after peroral administration is a crucial point. The gastric environment (ionic strength, low $\mathrm{pH}$ ) may destabilize the SLN and potentially lead to aggregation. However, it is possible to produce stable SLN dispersions by optimizing the surfactant/mixture for each lipid in vitro [44].

The drug release from SLN in the GIT is also dependent on the lipase/colipase activity for the GIT digestion of the lipid matrix. The lipase/colipase complex leads to a degradation of food lipids as a prestep of the absorption. In vitro 
degradation assay based on pancreas lipase/colipase complex have been developed to obtain basic information about the degradation velocity of SLN as a function of lipid and surfactant used in the production process $[45,46]$.

Lipid nanoparticles show great promise to enhance oral bioavailability of some of the most poorly soluble drugs. The physical/chemical characteristics of lipid particulate systems are highly complex due to the existence of a variety of lipid assembly morphologies, the morphology-dependent solubility of drug, the interconversion of assembly morphology as a function of time and chemical structure, and the simultaneous lipid digestion [47].

\section{Lipid Nanoparticles as Drug Carriers}

Lipid nanoparticles show interesting features concerning therapeutic purposes. Their main characteristic is the fact that they are prepared with physiologically well-tolerated lipids [48]. During the last ten years, different substances have been entrapped into lipid nanoparticles (Table 1), ranging from lipophilic $[23,49]$ and hydrophilic molecules, including labile compounds, such as proteins and peptides [50].

3.1. Lipid Materials for Oral Administration. The term lipid is used here in a broader sense and includes triglycerides, partial glycerides, fatty acids, steroids, and waxes. However, it is required that matrix maintains the solid state at room temperature, and for this purpose, the selection of lipids is based on the evaluation of their polymorphic, crystallinity, miscibility, and physicochemical structure [11]. Table 2 shows the main lipids employed for the preparation of lipid nanoparticles.

Furthermore, the use of mono- and diglycerides as lipid matrix composition might increase drug solubility compared to highly pure lipids, such as monoacid triglycerides. Naturally occurring oils and fats comprise mixtures of mono-, di-, and triglycerides, containing fatty acids of varying chain length and degree of unsaturation $[25,86]$. The melting point of these lipids increases with the length of the fatty acid chain and decreases with the degree of unsaturation. The chemical nature of the lipid is also important, because lipids which form highly crystalline particles with a perfect lattice (e.g., monoacid triglycerides) lead to drug expulsion during storage time. Physicochemically stable lipid nanoparticles will be obtained only when the right surfactant and adjusted concentration have been employed [25].

\subsection{Determination of Optimal Hydrophile-Lipophile Balance} (HLB) Values for Lipid Nanoparticles Dispersions. Emulsifiers are essential to stabilize lipid nanoparticles dispersions and prevent particle agglomeration [87]. The choice of the ideal surfactant for a particular lipid matrix is based on the surfactant properties such as charge, molecular weight, chemical structure, and respective hydrophile-lipophile balance (HLB). All these properties affects the stability of the emulsion [10]. The HLB of an emulsifier is given by the balance between the size and strength of the hydrophilic and the lipophilic groups. All emulsifiers consist of a molecule that combines both hydrophilic and lipophilic groups. Griffin [88] defined the lipophilic emulsifiers as low HLB values (below 9), and hydrophilic emulsifiers as high HLB values (above 11). Those in the range of 9-11 are intermediate [89].

The HLB system is a useful method to choose the ideal emulsifier or blend of emulsifiers for the system, that is, if its required an oil-in-water (o/w), water-in-oil (w/o) [90], or a double $(\mathrm{w} / \mathrm{o} / \mathrm{w})$ emulsion. Matching the HLB value of the surfactant with the lipid will provide a suitable in vitro performance [91]. Table 3 depicts the mainly surfactants employed in the production of lipid nanoparticles.

Severino et al. [10] determined the HLB value for stearic acid and stearic acid capric/caprylic triglycerides to reach the best combination of surfactants (trioleate sorbitan and polysorbate 80) to obtain a stable lipid nanoparticles emulsion. The HLB value obtained for stearic acid was 15 and for stearic acid capric/caprylic triglycerides was 13.8. Sorbitan trioleate has an HLB value of 1.8 and polysorbate 80 of 15 , when used in the ratio $10: 90$, respectively. The surfactant mixtures prepared with different ratios provided well-defined HLB values. Polysorbate 80 is often used in combination with sorbitan trioleate due to their appropriate compatibility attributed to the similar chemical structure (same hydrocarbon chain length) for the production of stable emulsions.

\section{Biopharmaceutic and Pharmacokinetic Aspects}

Pharmacokinetic behaviour of drugs loaded in lipid nanoparticles need to differentiate if the drug is present as the released free form or as the associated form with lipid nanoparticles [106]. However, the poor aqueous solubility of some drugs turns difficult the design of pharmaceutical formulations and leads to variable bioavailability [107].

Xie et al. [108] reported a significant increase in the bioavailability and extended the systemic circulation of ofloxacin formulated in SLN, which could be attributed to a large surface area of the particles, improving the dissolution rate and level of ofloxacin in the presence of GIT fluids [109, 110], leading to shorter $T_{\max }$ and higher peak plasma concentration. In addition, lipid nanoparticles may adhere to the GIT wall or enter the intervillar spaces due to their small particle size, increasing their residence time [111]. Moreover, nanoparticles could protect the drug from chemical and enzymatic degradation and gradually release drug from the lipid matrix into blood, [112] resulting in a several-fold increase mean residence time compared with native drug. Han et al. [113] demonstrated that 5 oral doses of tilmicosin loaded in lipid nanoparticles administered every 10 days provided an equivalent therapeutic benefit to 46 daily doses of oral free drugs. In vitro release profile demonstrated that tilmicosin loaded in lipid nanoparticles followed a sustained release profile, and in vivo results showed that nanoparticles remained effective for a longer period of time, which was 
TABLE 1: Examples of drugs, miscellaneous active ingredients and macrocyclic skeletons incorporated into lipid nanoparticles.

\begin{tabular}{|c|c|c|c|c|}
\hline $\begin{array}{l}\text { Incorporated drug or } \\
\text { substance }\end{array}$ & Lipid & Advantageous & System & References \\
\hline $\begin{array}{l}3^{\prime} \text {-Azido- } 3^{\prime}- \\
\text { deoxythymidine } \\
\text { palmitate }\end{array}$ & Trilaurin & $\begin{array}{l}\text { Stable after autoclaving, and can be } \\
\text { lyophilized and rehydrated }\end{array}$ & SLN & {$[51]$} \\
\hline 5-Fluorouracil & $\begin{array}{c}\text { Dynasa } 114 \text { and Dynasan } \\
118 \\
\end{array}$ & $\begin{array}{l}\text { Prolonged release in simulated colonic } \\
\text { medium }\end{array}$ & SLN & {$[52]$} \\
\hline Apomorphine & $\begin{array}{c}\text { Glyceryl monostearate, } \\
\text { polyethylene glycol } \\
\text { monostearate }\end{array}$ & Enhanced the bioavailability in rats & SLN & {$[20]$} \\
\hline Ascorbyl palmitate & $\begin{array}{l}\text { Imwitor } 900 \text { and Labrafil } \\
\text { M1944 }\end{array}$ & $\begin{array}{l}\text { Viscoelastic measurements is appropriate } \\
\text { for topical/dermal application }\end{array}$ & NLC & {$[53]$} \\
\hline Baclofen & Stearic acid & $\begin{array}{l}\text { Significantly higher drug concentrations } \\
\text { in plasma }\end{array}$ & SLN & {$[54]$} \\
\hline Benzyl nicotinate & Dynasan 116 & Increased oxygenation in the skin & SLN & {$[55]$} \\
\hline Calcitonin & Trimyristin & $\begin{array}{l}\text { Improvement of the efficiency of such } \\
\text { carriers for oral delivery of proteins }\end{array}$ & SLN & {$[56]$} \\
\hline Camptothecin & $\begin{array}{l}\text { Monostearin and Soybean } \\
\text { Oil } 788\end{array}$ & $\begin{array}{l}\text { Stable and high performance delivery } \\
\text { system }\end{array}$ & NLC & {$[57,58]$} \\
\hline Clozapine & $\begin{array}{l}\text { Trimyristin, tripalmitin, } \\
\text { and tristearin }\end{array}$ & Improvement of bioavailability & SLN & {$[59]$} \\
\hline Cyclosporin A & $\begin{array}{l}\text { glyceryl monostearate, and } \\
\text { glyceryl palmitostearate }\end{array}$ & Controlled release & SLN & {$[60,61]$} \\
\hline Dexamethasone & Compritol 888 ATO & Drug delivery topical use & SLN & {$[62]$} \\
\hline Diazepam & $\begin{array}{l}\text { Compritol ATO } 888 \text { and } \\
\text { Imwitor } 900 \mathrm{~K}\end{array}$ & Prolonged release & SLN & {$[63]$} \\
\hline Doxorubicin & Glyceryl caprate & Enhanced apoptotic death & SLN & {$[64]$} \\
\hline $\begin{array}{l}\text { Gonadotropin release } \\
\text { hormone }\end{array}$ & Monostearin & Prolonged release & SLN & {$[65]$} \\
\hline Hydrocortisone & $\begin{array}{l}\text { Monoglyceride, chain } \\
\text { length of the fatty acid } \\
\text { moiety }\end{array}$ & SLN stable with release properties & SLN & {$[66]$} \\
\hline Ibuprofen & $\begin{array}{c}\text { stearic acid, triluarin, } \\
\text { tripalmitin }\end{array}$ & $\begin{array}{l}\text { Stable formulation and negligible cell } \\
\text { cytotoxicity }\end{array}$ & SLN & {$[67]$} \\
\hline Idarubicin & Emulsifying wax & Potential to deliver anticancer drugs & SLN & {$[68]$} \\
\hline Insulin & $\begin{array}{l}\text { Stearic acid, octadecyl } \\
\text { alcohol, cetyl palmitate, } \\
\text { glyceryl monostearate, } \\
\text { glyceryl palmitostearate, } \\
\text { glyceryl tripalmitate, } \\
\text { glyceryl behenate }\end{array}$ & Promising for oral delivery of proteins & SLN & {$[50]$} \\
\hline Ketoprofen & $\begin{array}{l}\text { mixture of beeswax and } \\
\text { carnauba wax }\end{array}$ & $\begin{array}{l}\text { SLN with beeswax content exhibited } \\
\text { faster drug release as compared carnauba } \\
\text { wax }\end{array}$ & SLN & {$[69]$} \\
\hline Lopinavir & Compritol 888 ATO & Bioavailability enhanced & SLN & {$[70]$} \\
\hline Nimesulide & $\begin{array}{c}\text { Glyceryl behenate, } \\
\text { palmitostearate, glyceryl } \\
\text { tristearate }\end{array}$ & Sustained drug release & SLN & {$[71]$} \\
\hline Penciclovir & Glyceryl monostearate & Provide a good skin targeting & SLN & {$[72]$} \\
\hline Progesterone & $\begin{array}{c}\text { Monostearin, stearic acid } \\
\text { and oleic acid }\end{array}$ & $\begin{array}{l}\text { Potential drug delivery system for oral } \\
\text { administration }\end{array}$ & NLC & {$[73,74]$} \\
\hline Repaglinide & $\begin{array}{l}\text { Glycerol monostearate and } \\
\text { tristearin }\end{array}$ & $\begin{array}{l}\text { Toxicity study indicated that the SLN } \\
\text { were well tolerated }\end{array}$ & SLN & {$[22,49]$} \\
\hline Salbutamol sulphate & Monostearin and PEG2000 & $\begin{array}{l}\text { Formulation accelerate release of } \\
\text { hydrophilic small molecule drugs }\end{array}$ & SLN & {$[75]$} \\
\hline Tetracycline & $\begin{array}{l}\text { glyceryl monostearate and } \\
\text { stearic acid }\end{array}$ & Sustained release & SLN & {$[76]$} \\
\hline
\end{tabular}


TABLE 2: Lipids used for lipid nanoparticles production.

\begin{tabular}{lc}
\hline Lipids & References \\
\hline Triglycerides & \\
Trimyristin (Dynasan 114) & {$[11]$} \\
Tripalmitin (Dynasan 116) & {$[77]$} \\
Tristearin (Dynasan 118) & {$[11]$} \\
Mono, di and triglycerides mixtures & \\
Witeposol bases & {$[78]$} \\
Glyceryl monostearate (Imwitor 900) & {$[22]$} \\
Glyceryl behenate (Compritol 888 ATO) & {$[79]$} \\
Glyceryl palmitostearate (Precirol ATO 5) & {$[80]$} \\
Waxes & \\
Beeswax & {$[81]$} \\
Cetyl palmitate & {$[82]$} \\
Hard fats & \\
Stearic acid & {$[10]$} \\
Palmitic acid & {$[83]$} \\
Behenic acid & {$[84]$} \\
Other lipids & \\
Miglyol 812 & {$[11]$} \\
Paraffin & {$[85]$} \\
\hline
\end{tabular}

TABLE 3: Emulsifiers used for the production of lipid nanoparticles.

\begin{tabular}{lcc}
\hline Emulsifiers/coemulsifiers & HLB & References \\
\hline Lecithin & $4-9$ & {$[92,93]$} \\
Poloxamer 188 & 29 & {$[94]$} \\
Poloxamer 407 & 21.5 & {$[56,95]$} \\
Tyloxapol & 13 & {$[96]$} \\
Polysorbate 20 & 16.7 & {$[92]$} \\
Polysorbate 60 & 14.9 & {$[97]$} \\
Polysorbate 80 & 15 & {$[10,11]$} \\
Sodium cholate & 18 & {$[98]$} \\
Sodium glycocholate & 14.9 & {$[99]$} \\
Taurodeoxycholic acid sodium & $13-14$ & {$[100]$} \\
Butanol and Butyric acid & $7-9$ & {$[101]$} \\
Cetylpyridinium chloride & $\sim 15$ & {$[102]$} \\
Sodium dodecyl sulphate & 40 & {$[103]$} \\
Sodium oleate & 18 & {$[99]$} \\
Polyvinyl alcohol & $15-19$ & {$[104]$} \\
Cremophor EL & $12-14$ & {$[105]$} \\
\hline
\end{tabular}

attributed to sustained release of the drug and also to enhanced antibacterial activity by the SLN.

Pandita et al. [114] developed paclitaxel loaded in SLN with the aim at improving the oral bioavailability of this antineoplastic drug. In vitro studies of SLN formulation exhibited an initial low burst effect within $24 \mathrm{~h}$ followed by a slow and sustained release. Statistical analysis of in vivo experiments concluded that the oral bioavailability of paclitaxel loaded in SLN was significantly higher than the control group.

Yuan et al. [115] produced stearic acid-SLN with a fluorescence marked for evaluation of in vivo pathway by oral administration. About $30 \%$ of SLN transport was efficient, where particles were absorbed following linear mechanism in the GIT. The release profile in plasma increased with the increasing of dosage depicting two concentration peaks. The first peak of SLN in blood took place during 1-2 h, attributed to the fast uptake of SLN from the GIT into systematic circulation. Drug concentration began to decrease attributed to the uptake by and the distribution of SLN among particular organs. The second peak occurred at about $6-8 \mathrm{~h}$, and the maximum concentrations were lower than that of the first peak.

\section{Toxicology}

Lipid nanoparticles are well tolerated in living systems, since they are made from physiological compounds leading to the metabolic pathways $[22,28]$. For this purpose, studies focusing on nanotoxicology comprise cytotoxicity and genotoxicity analysis [116]. However, such effects often occur first at rather in high concentrations and the subtler effects that arise at lower concentrations, without necessarily causing cell death, also need to be considered. One the most important effect is DNA damage, since an increased genetic instability is associated with cancer development [117]. The interaction with proteins and cells are an essential focus in assessing and understanding compatibility and toxicity. Cell and nanoparticle reactions of interest include cellular uptake and processing of nanoparticle in various routes, effects on cell signalling, membrane perturbations, influence on the cellular electron transfer cascades, production of cytokines, chemokines, and reactive oxygen species (ROS), transcytosis and intercellular transport, gene regulation overt toxic reactivity, no observable toxicity, and cell necrosis or apoptosis. In vitro culture of cell lines or primary cells on plastic plates are employed in a wide varieties of assays and reflect the variety of possible physiologic responses to nanoparticles in vivo and all possible cell processing routes and natural reactions [118].

Silva et al. [119] studied the toxicity of SLN and risperidone loaded SLN with Caco-2 cells by (4,5-dimthylthiazol2-yl)2,5-diphenyl-tetrazolium bromide (MTT) assay. The results suggest that all formulations evaluated are biocompatible with Caco-2 cells and well tolerated by the GIT. Similar results have been reported elsewhere $[120,121]$. This test evaluates the mitochondrial function as a measurement of cell viability, which allows the detection of dead cells before they lose their integrity and shape. The amount of viable cells after SLN exposure was performed by the MTT assay with Caco-2 cell models, which are a well-established in vitro model that mimics the intestinal barrier and is often used to assess the permeability and transport of oral drugs [122]. Other authors have also reported that SLN 
show biocompatibility, which increase their attractiveness for drug-delivery applications [120].

\section{Marketed Products and Current Studies}

Since early nineties, researchers turned their attention to lipid nanoparticles because of their nontoxicity and cost/effectiveness relationship [12]. In spite of the advantages, formulating with lipid nanoparticles has been suffering some drawbacks. Because of the GIT conditions, most of promising drugs do not reach clinical trials. The stability of particles must be comprehensively tested due to $\mathrm{pH}$ changes and ionic strength as well as the drug release upon enzymatic degradation [123]. Lipid nanoparticles absorption through GIT occurs via transcellular (through M cells or enterocytes) or paracellular (diffusion between cells). If the major drug uptake occurs through $\mathrm{M}$ cells, the portal vein to the liver is bypassed, resulting in higher drug concentrations to the lymph rather than to plasma [124]. Despite the low number of lipid nanoparticles formulations on the market for drug delivery, Mucosolvan retard capsules (BoehringerIngelheim) is a story of success [125]. Mucosolvan retard capsules was the first generation. It was produced by highspeed stirring of a melted lipid phase in a hot surfactant solution obtaining an emulsion. This emulsion was then cooled down to room temperature obtaining the so-called "lipid nanopellets for oral administration" [126].

Successful in vivo studies also include rifampicin, isoniazid, and pyrazinamide that are used in tuberculosis treatment. These drugs achieved higher bioavailability when incorporated into SLN compared to the free solutions. Rifampicin has poor cellular penetration which requires high doses to reach effective concentrations. Rifamsolin is a rifampicin-loaded SLN under preclinical phase by AlphaRx. The methodology employed for production is acceptable by the regulatory agencies and has been addressed by various papers and patents [127].

Poor water-soluble drugs, as camptothecin, vinpocetine, and fenofibrate, can have their solubilization improved if incorporated into SLN [124, 128]. Another example is insulin, commonly administered parenterally in the treatment of diabetes mellitus. Injections are often painful and must be administered daily, which result in low patient compliance [129]. Unfortunately, oral administration of insulin, produced by solvent emulsification-evaporation method based on a w/o/w double emulsion, has limitations such as low bioavailability due to degradation in the stomach, inactivation and degradation by proteolytic enzymes, and low permeability across the intestinal epithelium because of lack of lipophilicity and high molecular weight [124, 129]. The main advantages of incorporate insulin into SLN would be the enhancement of transmucosal transport and protection from the degradation in the GIT.

\section{Conclusions}

Lipids and lipid nanoparticles are promising for oral and peroral administration route for drugs, proteins, and peptides.
Theses matrices are able to promoting controlled release of drugs in GIT and reducing absorption variability. In addition, these matrices can be absorption as food lipids together with drugs improving the bioavailability. These systems present several advantages, including drug protection and excipients of GRAS status, which decreases the danger of acute and chronic toxicity. In addition, the oral administration of lipids nanoparticles is possible as aqueous dispersion or alternatively transformed into a traditional dosage forms such as tablets, pellets, capsules, or powders in sachets.

\section{Acknowledgments}

The authors wish to acknowledge Fundação para a Ciência e Tecnologia do Ministério da Ciência e Tecnologia, under reference no. ERA-Eula/0002/2009. Sponsorship of P. Severino was received from CAPES (Coordenação Aperfeiçoamento de Pessoal de Nivel Superior) and FAPESP (Fundação de Amparo a Pesquisa). Sponsorship of T. Andreani was received from Fundação para Ciência e Tecnologia (SFRH/ $\mathrm{BD} / 60640 / 2009)$.

\section{References}

[1] T. Eldem, P. Speiser, and A. Hinkal, "Optimization of spraydried and congelated lipid micropellets and caracterization of their surface morphology by scanning electron microscopy," Pharmaceutical Research, vol. 8, pp. 47-54, 1991.

[2] P. Speiser, EP 0167825, assignee. Lipid nanopellets als Tragersystem fur Arzneimittel zur peroralen Anwendung, 1990.

[3] A. J. Domb, "Long acting injectable oxytetracycline-liposphere formulations," International Journal of Pharmaceutics, vol. 124, no. 2, pp. 271-278, 1995.

[4] A. J. Domb, "Lipospheres for controlled delivery of substances," 1993.

[5] A. J. Domb, "Liposphere parenteral delivery system," Proceedings of the Controlled Release Society, no. 20, pp. 121-122, 1993.

[6] K. Manjunath, J. S. Ready, and V. Venkateswarlu, "Solid lipid nanoparticles as drug delivery systems," Methods and Findings in Experimental and Clinical Pharmacology, vol. 27, no. 2, pp. 127-144, 2005.

[7] X. Qi, L. Wang, and J. Zhu, "Water-in-oil-in-water double emulsions: an excellent delivery system for improving the oral bioavailability of pidotimod in rats," Journal of Pharmaceutical Sciences, vol. 100, no. 6, pp. 2203-2211, 2011.

[8] M. J. Morilla, D. M. Gomez, P. Cabral et al., "M cells prefer archaeosomes: an in vitro/in vivo snapshot upon oral gavage in rats," Current Drug Delivery, vol. 8, no. 3, pp. 320-329, 2011.

[9] C. F. Da Silva, P. Severino, F. Martins, M. V. Chaud, and M. H. A. Santana, "The intestinal permeation of didanosine from granules containing microspheres using the everted gut sac model," Journal of Microencapsulation, vol. 26, no. 6, pp. 523$528,2009$.

[10] P. Severino, S. C. Pinho, E. B. Souto, and M. H. A. Santana, "Polymorphism, crystallinity and hydrophilic-lipophilic balance of stearic acid and stearic acid-capric/caprylic triglyceride matrices for production of stable nanoparticles," Colloids and Surfaces B, vol. 86, no. 1, pp. 125-130, 2011. 
[11] P. Severino, S. C. Pinho, E. B. Souto, and M. H. A. Santana, "Crystallinity of Dynasan114 and Dynasan118 matrices for the production of stable Miglyol-loaded nanoparticles," Journal of Thermal Analysis and Calorimetry. In press.

[12] R. H. Müller, W. Mehnert, J. S. Lucks et al., "Solid lipid nanoparticles (SLN) - an alternative colloidal carrier system for controlled drug delivery," European Journal of Pharmaceutics and Biopharmaceutics, vol. 41, no. 1, pp. 62-69, 1995.

[13] R. H. Müller and J. S. Lucks, "Azneistoffräger aus festen Lipidteilchen-feste Lipid Nanosphären (SLN)," Germany, 1996.

[14] M. R., inventor Gasco, "Method for producing solid lipid microspheres having a narrow size distribution," Italy, 1993.

[15] M. Trotta, M. E. Carlotti, M. Gallarate, G. P. Zara, E. Muntoni, and L. Battaglia, "Insulin-loaded SLN prepared with the emulsion dilution technique: in vivo tracking of nanoparticles after oral administration to rats," Journal of Dispersion Science and Technology, vol. 32, no. 7, pp. 10411045, 2011.

[16] E. B. Souto and R. H. Müller, "Lipid nanoparticles-effect on bioavailability and pharmacokinetics changes," in Handbook of Experimental Pharmacology-Novel Drug Delivery Approaches, M. Schäfer-Korting, Ed., vol. 197, pp. 115-141, Springer, Berlin, Germany, 2009.

[17] M. A. Schubert and C. C. Müller-Goymann, "Characterisation of surface-modified solid lipid nanoparticles (SLN): influence of lecithin and nonionic emulsifier," European Journal of Pharmaceutics and Biopharmaceutics, vol. 61, pp. 77-86, 2005.

[18] R. H. Müller, S. Maaßen, H. Weyhers, F. Specht, and J. S. Lucks, "Cytotoxicity of magnetite-loaded polylactide, polylactide/glycolide particles and solid lipid nanoparticles," International Journal of Pharmaceutics, vol. 138, no. 1, pp. 8594, 1996.

[19] R. H. Müller, K. Mäder, and S. Gohla, "Solid lipid nanoparticles (SLN) for controlled drug delivery-a review of the state of the art," European Journal of Pharmaceutics and Biopharmaceutics, vol. 50, no. 1, pp. 161-177, 2000.

[20] M. J. Tsai, Y. B. Huang, P. C. Wu et al., "Oral apomorphine delivery from solid lipid nanoparticleswith different monostearate emulsifiers: pharmacokinetic and behavioral evaluations," Journal of Pharmaceutical Sciences, vol. 100, no. 2, pp. 547-557, 2011

[21] S. Mukherjee, S. Ray, and R. S. Thakur, "Solid lipid nanoparticles: a modern formulation approach in drug delivery system," Indian Journal of Pharmaceutical Sciences, vol. 71, no. 4, pp. 349-358, 2009.

[22] M. K. Rawat, A. Jain, and S. Singh, "In vivo and cytotoxicity evaluation of repaglinide-loaded binary solid lipid nanoparticles after oral administration to rats," Journal of Pharmaceutical Sciences, vol. 100, no. 6, pp. 2406-2417, 2011.

[23] C.-F. Luo, M. Yuan, M.-S. Chen et al., "Pharmacokinetics, tissue distribution and relative bioavailability of puerarin solid lipid nanoparticles following oral administration," International Journal of Pharmaceutics, vol. 410, no. 1-2, pp. 138-144, 2011.

[24] L. Hu, Q. Xing, J. Meng, and C. Shang, "Preparation and enhanced oral bioavailability of cryptotanshinone-loaded solid lipid nanoparticles," AAPS PharmSciTech, vol. 11, no. 2, pp. 582-587, 2010.

[25] E. B. Souto and R. H. Müller, "Lipid nanoparticles: effect on bioavailability and pharmacokinetic changes," Handbook of Experimental Pharmacology, vol. 197, pp. 115-141, 2010.
[26] B. W. K. Siekmann, "Submicron lipid suspensions (solid lipid nanoparticles) versus lipid nanoemulsions: similarities and differences," Amesterdam, The Netherlands, 1998.

[27] R. H. Müller, W. Mehnert, and E. B. Souto, "Solid lipid nanoparticles (SLN) and nanostructured lipid carriers (NLC) for dermal delivery," Hong-Kong, 2005.

[28] S. A. Wissing, O. Kayser, and R. H. Müller, "Solid lipid nanoparticles for parenteral drug delivery," Advanced Drug Delivery Reviews, vol. 56, no. 9, pp. 1257-1272, 2004.

[29] S. Das and A. Chaudhury, "Recent advances in lipid nanoparticle formulations with solid matrix for oral drug delivery," AAPS PharmSciTech, vol. 12, no. 1, pp. 62-76, 2010.

[30] H. Bunjes, "Lipid nanoparticles for the delivery of poorly water-soluble drugs," Journal of Pharmacy and Pharmacology, vol. 62, no. 11, pp. 1637-1645, 2010.

[31] S. Singh, A. K. Dobhal, A. Jain, J. K. Pandit, and S. Chakraborty, "Formulation and evaluation of solid lipid nanoparticles of a water soluble drug: zidovudine," Chemical and Pharmaceutical Bulletin, vol. 58, no. 5, pp. 650-655, 2010.

[32] J. F. Fangueiro, E. Gonzalez-Mira, P. Martins-Lopes, M. A. Egea, M. L. Garcia, and S. B. Souto, "A novel lipid nanocarrier for insulin delivery: production, characterization and toxicity testing," Pharmaceutical Development and Technology. In press.

[33] S. Das, W. K. Ng, P. Kanaujia, S. Kim, and R. B. H. Tan, "Formulation design, preparation and physicochemical characterizations of solid lipid nanoparticles containing a hydrophobic drug: effects of process variables," Colloids and Surfaces B, vol. 88, no. 1, pp. 483-489, 2011.

[34] C. Olbrich, A. Gessner, O. Kayser, and R. H. Müller, "Lipiddrug-conjugate (LDC) nanoparticles as novel carrier system for the hydrophilic antitrypanosomal drug diminazenediaceturate," Journal of Drug Targeting, vol. 10, no. 5, pp. 387-396, 2002.

[35] L. Sek, C. J. H. Porter, A. M. Kaukonen, and W. N. Charman, "Evaluation of the in-vitro digestion profiles of long and medium chain glycerides and the phase behaviour of their lipolytic products," Journal of Pharmacy and Pharmacology, vol. 54, no. 1, pp. 29-41, 2002.

[36] R. H. Müller and C. M. Keck, "Challenges and solutions for the delivery of biotech drugs - a review of drug nanocrystal technology and lipid nanoparticles," Journal of Biotechnology, vol. 113, no. 1-3, pp. 151-170, 2004.

[37] E. B. Souto, S. Doktorovova, and P. Boonme, "Lipid nanocarriers-based semisolids: review on materials and end product formulations," Journal of Drug Delivery Science and Technology, vol. 21, pp. 43-54, 2011.

[38] C. Liu, D. Liu, F. Bai, J. Zhang, and N. Zhang, "In vitro and in vivo studies of lipid-based nanocarriers for oral N3-o-toluylfluorouracil delivery," Drug Delivery, vol. 17, no. 5, pp. 352363, 2010.

[39] D. Shukla, S. Chakraborty, S. Singh, and B. Mishra, "Lipidbased oral multiparticulate formulations-advantages, technological advances and industrial applications," Expert Opinion on Drug Delivery, vol. 8, no. 2, pp. 207-224, 2011.

[40] H. Weyhers, S. Ehlers, H. Hahn, E. B. Souto, and R. H. Müller, "Solid lipid nanoparticles (SLN)—Effects of lipid composition on in vitro degradation and in vivo toxicity," Pharmazie, vol. 61, no. 6, pp. 539-544, 2006.

[41] W. Mehnert and K. Mäder, "Solid lipid nanoparticles: production, characterization and applications," Advanced Drug Delivery Reviews, vol. 47, no. 2-3, pp. 165-196, 2001. 
[42] V. Jenning, A. F. Thünemann, and S. H. Gohla, "Characterisation of a novel solid lipid nanoparticle carrier system based on binary mixtures of liquid and solid lipids," International Journal of Pharmaceutics, vol. 199, no. 2, pp. 167-177, 2000.

[43] M. J. Montisci, A. Dembri, G. Giovannuci, H. Chacun, D. Duchêne, and G. Ponchel, "Gastrointestinal transit and mucoadhesion of colloidal suspensions of Lycopersicon esculentum L. and Lotus tetragonolobus lectin-PLA microsphere conjugates in rats," Pharmaceutical Research, vol. 18, no. 6, pp. 829-837, 2001.

[44] E. Zimmermann and R. H. Müller, "Electrolyte- and pHstabilities of aqueous solid lipid nanoparticle (SLN) dispersions in artificial gastrointestinal media," European Journal of Pharmaceutics and Biopharmaceutics, vol. 52, no. 2, pp. 203210, 2001.

[45] H. Reithmeier, J. Herrmann, and A. Göpferich, "Development and characterization of lipid microparticles as a drug carrier for somatostatin," International Journal of Pharmaceutics, vol. 218, no. 1-2, pp. 133-143, 2001.

[46] J. Kristl, B. Volk, P. Ahlin, K. Gombač, and M. Šentjurc, "Interactions of solid lipid nanoparticles with model membranes and leukocytes studied by EPR," International Journal of Pharmaceutics, vol. 256, no. 1-2, pp. 133-140, 2003.

[47] P. M. Bummer, "Physical chemical considerations of lipidbased oral drug delivery—solid lipid nanoparticles," Critical Reviews in Therapeutic Drug Carrier Systems, vol. 21, no. 1, pp. 1-19, 2004.

[48] V. Kakkar, S. Singh, D. Singla, and I. P. Kaur, "Exploring solid lipid nanoparticles to enhance the oral bioavailability of curcumin," Molecular Nutrition and Food Research, vol. 55, no. 3, pp. 495-503, 2011.

[49] M. K. Rawat, A. Jain, and S. Singh, "Studies on binary lipid matrix based solid lipid nanoparticles of repaglinide: in vitro and in vivo evaluation," Journal of Pharmaceutical Sciences, vol. 100, no. 6, pp. 2366-2378, 2011.

[50] R. Yang, R. Gao, F. Li, H. He, and X. Tang, "The influence of lipid characteristics on the formation, in vitro release, and in vivo absorption of protein-loaded SLN prepared by the double emulsion process," Drug Development and Industrial Pharmacy, vol. 37, no. 2, pp. 139-148, 2011.

[51] H. Heiati, R. Tawashi, and N. C. Phillips, "Drug retention and stability of solid lipid nanoparticles containing azidothymidine palmitate after autoclaving, storage and lyophilization," Journal of Microencapsulation, vol. 15, no. 2, pp. 173-184, 1998.

[52] A. E. B. Yassin, M. D. Khalid Anwer, H. A. Mowafy, I. M. ElBagory, M. A. Bayomi, and I. A. Alsarra, "Optimization of 5fluorouracil solid-lipid nanoparticles: a preliminary study to treat colon cancer," International Journal of Medical Sciences, vol. 7, no. 6, pp. 398-408, 2010.

[53] V. Teeranachaideekul, E. Souto, R. Müller, and V. B. Junyaprasert, "Physicochemical characterization and in vitro release studies of ascorbyl palmitate-loaded semi-solid nanostructured lipid carriers (NLC gels)," Journal of Microencapsulation, vol. 25, no. 2, pp. 111-120, 2008.

[54] L. Priano, G. P. Zara, N. El-Assawy et al., "Baclofen-loaded solid lipid nanoparticles: preparation, electrophysiological assessment of efficacy, pharmacokinetic and tissue distribution in rats after intraperitoneal administration," European Journal of Pharmaceutics and Biopharmaceutics, vol. 79, no. 1, pp. 135-141, 2011.

[55] M. Krzic, M. Sentjurc, and J. Kristl, "Improved skin oxygenation after benzyl nicotinate application in different carriers as measured by EPR oximetry in vivo," Journal of Controlled Release, vol. 70, no. 1-2, pp. 203-211, 2001.

[56] S. Martins, A. C. Silva, D. C. Ferreira, and E. B. Souto, "Improving oral absorption of samon calcitonin by trimyristin lipid nanoparticles," Journal of Biomedical Nanotechnology, vol. 5, no. 1, pp. 76-83, 2009.

[57] X. Zhang, W. Pan, L. Gan, C. Zhu, Y. Gan, and S. Nie, "Preparation of a dispersible PEGylate nanostructured lipid carriers (NLC) loaded with 10-hydroxycamptothecin by spray-drying," Chemical and Pharmaceutical Bulletin, vol. 56, no. 12, pp. 1645-1650, 2008.

[58] Z. R. Huang, S. C. Hua, Y. L. Yang, and J. Y. Fang, "Development and evaluation of lipid nanoparticles for camptothecin delivery: a comparison of solid lipid nanoparticles, nanostructured lipid carriers, and lipid emulsion," Acta Pharmacologica Sinica, vol. 29, no. 9, pp. 1094-1102, 2008.

[59] K. Manjunath and V. Venkateswarlu, "Pharmacokinetics, tissue distribution and bioavailability of clozapine solid lipid nanoparticles after intravenous and intraduodenal administration," Journal of Controlled Release, vol. 107, no. 2, pp. 215228, 2005.

[60] J. K. Varia, S. S. Dodiya, and K. K. Sawant, "Cyclosporine a loaded solid lipid nanoparticles: optimization of formulation, process variable and characterization," Current Drug Delivery, vol. 5, no. 1, pp. 64-69, 2008.

[61] R. H. Müller, S. A. Runge, V. Ravelli, A. F. Thünemann, W. Mehnert, and E. B. Souto, "Cyclosporine-loaded solid lipid nanoparticles (SLN): drug-lipid physicochemical interactions and characterization of drug incorporation," European Journal of Pharmaceutics and Biopharmaceutics, vol. 68, no. 3, pp. 535-544, 2008.

[62] G. Chen, S. X. Hou, P. Hu, Q. H. Hu, D. D. Guo, and Y. Xiao, "In vitro dexamethasone release from nanoparticles and its pharmacokinetics in the inner ear after administration of the drug-loaded nanoparticles via the round window," Journal of Southern Medical University, vol. 28, no. 6, pp. 1022-1024, 2008.

[63] G. Abdelbary and R. H. Fahmy, "Diazepam-Loaded solid lipid nanoparticles: design and characterization," AAPS PharmSciTech, vol. 10, no. 1, pp. 211-219, 2009.

[64] K. W. Kang, M. K. Chun, O. Kim et al., "Doxorubicin-loaded solid lipid nanoparticles to overcome multidrug resistance in cancer therapy," Nanomedicine, vol. 6, no. 2, pp. 210-213, 2010.

[65] F. Q. Hu, Y. Hong, and H. Yuan, "Preparation and characterization of solid lipid nanoparticles containing peptide," International Journal of Pharmaceutics, vol. 273, no. 1-2, pp. 29-35, 2004.

[66] L. B. Jensen, E. Magnussson, L. Gunnarsson, C. Vermehren, H. M. Nielsen, and K. Petersson, "Corticosteroid solubility and lipid polarity control release from solid lipid nanoparticles," International Journal of Pharmaceutics, vol. 390, no. 1, pp. 53-60, 2010.

[67] S. G. Potta, S. Minemi, R. K. Nukala et al., "Preparation and characterization of ibuprofen solid lipid nanoparticles with enhanced solubility," Journal of Microencapsulation, vol. 28, no. 1, pp. 74-81, 2011.

[68] P. Ma, X. Dong, C. L. Swadley et al., "Development of idarubicin and doxorubicin solid lipid nanoparticles to overcome Pgp-mediated multiple drug resistance in leukemia," Journal of Biomedical Nanotechnology, vol. 5, no. 2, pp. 151-161, 2009. 
[69] S. Kheradmandnia, E. Vasheghani-Farahani, M. Nosrati, and F. Atyabi, "Preparation and characterization of ketoprofenloaded solid lipid nanoparticles made from beeswax and carnauba wax," Nanomedicine, vol. 6, no. 6, pp. 753-759, 2010.

[70] M. R. Aji Alex, A. J. Chacko, S. Jose, and E. B. Souto, "Lopinavir loaded solid lipid nanoparticles (SLN) for intestinal lymphatic targeting," European Journal of Pharmaceutical Sciences, vol. 42, no. 1-2, pp. 11-18, 2011.

[71] V. B. Patravale and A. V. Ambarkhane, "Study of solid lipid nanoparticles with respect to particle size distribution and drug loading," Pharmazie, vol. 58, no. 6, pp. 392-395, 2003.

[72] Q. Lv, A. Yu, Y. Xi et al., "Development and evaluation of penciclovir-loaded solid lipid nanoparticles for topical delivery," International Journal of Pharmaceutics, vol. 372, no. 1-2, pp. 191-198, 2009.

[73] H. Yuan, L. L. Wang, Y. Z. Du, J. You, F. Q. Hu, and S. Zeng, "Preparation and characteristics of nanostructured lipid carriers for control-releasing progesterone by meltemulsification," Colloids and Surfaces B, vol. 60, no. 2, pp. 174-179, 2007.

[74] R. Cavalli, E. Peira, O. Caputo, and M. R. Gasco, "Solid lipid nanoparticles as carriers of hydrocortisone and progesterone complexes with $\beta$-cyclodextrins," International Journal of Pharmaceutics, vol. 182, no. 1, pp. 59-69, 1999.

[75] Y. Hong, F. Q. Hu, and H. Yuan, "Effect of PEG2000 on drug delivery characterization from solid lipid nanoparticles," Pharmazie, vol. 61, no. 4, pp. 312-315, 2006.

[76] X.-M. Xu, Y.-S. Wang, R.-Y. Chen et al., "Formulation and pharmacokinetic evaluation of tetracycline-loaded solid lipid nanoparticles for subcutaneous injection in mice," Chemical and Pharmaceutical Bulletin, vol. 59, no. 2, pp. 260-265, 2011.

[77] E. Başaran, M. Demirel, B. Sirmagül, and Y. Yazan, "Сyclosporine-a incorporated cationic solid lipid nanoparticles for ocular delivery," Journal of Microencapsulation, vol. 27, no. 1, pp. 37-47, 2010.

[78] K. Vivek, H. Reddy, and R. S. R. Murthy, "Investigations of the effect of the lipid matrix on drug entrapment, in vitro release, and physical stability of olanzapine-loaded solid lipid nanoparticles," AAPS PharmSciTech, vol. 8, no. 4, article no. 83, 2007.

[79] M. Shah, K. Chuttani, A. K. Mishra, and K. Pathak, "Oral solid compritol 888 ATO nanosuspension of simvastatin: optimization and biodistribution studies," Drug Development and Industrial Pharmacy, vol. 37, no. 5, pp. 526-537, 2011.

[80] A. del Pozo-Rodríguez, D. Delgado, M. A. Solinís et al., "Solid lipid nanoparticles as potential tools for gene therapy: in vivo protein expression after intravenous administration," International Journal of Pharmaceutics, vol. 385, no. 1-2, pp. 157-162, 2010.

[81] J. Zhang and E. Smith, "Percutaneous permeation of betamethasone 17-valerate incorporated in lipid nanoparticles," Journal of Pharmaceutical Sciences, vol. 100, no. 3, pp. 896-903, 2011.

[82] L. Montenegro, A. Campisi, M. G. Sarpietro et al., "In vitro evaluation of idebenone-loaded solid lipid nanoparticles for drug delivery to the brain," Drug Development and Industrial Pharmacy, vol. 37, no. 6, pp. 737-746, 2011.

[83] S. Xie, L. Zhu, Z. Dong, Y. Wang, X. Wang, and W. Zhou, "Preparation and evaluation of ofloxacin-loaded palmitic acid solid lipid nanoparticles," International Journal of Nanomedicine, vol. 6, pp. 547-555, 2011.
[84] L. Battaglia, M. Gallarate, R. Cavalli, and M. Trotta, "Solid lipid nanoparticles produced through a coacervation method," Journal of Microencapsulation, vol. 27, no. 1, pp. 78-85, 2010.

[85] N. Schöler, H. Hahn, R. H. Müller, and O. Liesenfeld, "Effect of lipid matrix and size of solid lipid nanoparticles (SLN) on the viability and cytokine production of macrophages," International Journal of Pharmaceutics, vol. 231, no. 2, pp. 167-176, 2002.

[86] D. J. Hauss, “Oral lipid-based formulations," Advanced Drug Delivery Reviews, vol. 59, no. 7, pp. 667-676, 2007.

[87] T. M. Goppert and R. H. Muller, "Polysorbate-stabilized solid lipid nanoparticles as colloidal carriers for intravenous targeting of drugs to the brain: comparison of plasma protein adsorption patterns," Journal of Drug Targeting, vol. 13, no. 3, pp. 179-187, 2005.

[88] W. C. Griffin, "Classification of surface-active agents by HLB," Journal of the Society of Cosmetic Chemists, vol. 1, p. 311, 1949.

[89] R. Kinget, "Classification of the most important surface active agents being used for the formulation of drugs and cosmetic products," Farmaceutisch Tijdschrift voor Belgie, vol. 75, no. 4, pp. 3-15, 1998.

[90] W. C. Griffin, "Calculation of HLB valuess of nonionic surfactants," Journal of the Society of Cosmetic Chemists, vol. 5, pp. 249-256, 1954.

[91] T. Schmidts, D. Dobler, C. Nissing, and F. Runkel, "Influence of hydrophilic surfactants on the properties of multiple W/O/ W emulsions," Journal of Colloid and Interface Science, vol. 338, no. 1, pp. 184-192, 2009.

[92] J. Varshosaz, M. Tabbakhian, and M. Y. Mohammadi, "Formulation and optimization of solid lipid nanoparticles of buspirone $\mathrm{HCl}$ for enhancement of its oral bioavailability," Journal of Liposome Research, vol. 20, no. 4, pp. 286-296, 2010.

[93] S. Jain, S. Jain, P. Khare, A. Gulbake, D. Bansal, and S. K. Jain, "Design and development of solid lipid nanoparticles for topical delivery of an anti-fungal agent," Drug Delivery, vol. 17, no. 6, pp. 443-451, 2010.

[94] M. A. Kalam, Y. Sultana, A. Ali, M. Aqil, A. K. Mishra, and K. Chuttani, "Preparation, characterization, and evaluation of gatifloxacin loaded solid lipid nanoparticles as colloidal ocular drug delivery system," Journal of Drug Targeting, vol. 18, no. 3, pp. 191-204, 2010.

[95] T. M. Göppert and R. H. Müller, "Adsorption kinetics of plasma proteins on solid lipid nanoparticles for drug targeting," International Journal of Pharmaceutics, vol. 302, no. 1-2, pp. 172-186, 2005.

[96] J. Kristl, K. Teskac, M. Milek, and I. Mlinaric-Rascan, "Surface active stabilizer Tyloxapol in colloidal dispersions exerts cytostatic effects and apoptotic dismissal of cells," Toxicology and Applied Pharmacology, vol. 232, no. 2, pp. 218-225, 2008.

[97] H. Thrandur, T. S. Awad, K. Kristberg, A. D. Eric, J. M. A. David, and W. Jochen, "Impact of surfactant properties on oxidative stability of $\beta$-carotene encapsulated within solid lipid nanoparticles," Journal of Agricultural and Food Chemistry, vol. 57, no. 17, pp. 8033-8040, 2009.

[98] J. Liu, T. Gong, H. Fu et al., "Solid lipid nanoparticles for pulmonary delivery of insulin," International Journal of Pharmaceutics, vol. 356, no. 1-2, pp. 333-344, 2008.

[99] H. Bunjes, M. H. J. Koch, and K. Westesen, "Influence of emulsifiers on the crystallization of solid lipid nanoparticles," 
Journal of Pharmaceutical Sciences, vol. 92, no. 7, pp. 15091520, 2003.

[100] M. Trotta, F. Debernardi, and O. Caputo, "Preparation of solid lipid nanoparticles by a solvent emulsification-diffusion technique," International Journal of Pharmaceutics, vol. 257, no. 1-2, pp. 153-160, 2003.

[101] T. Wang, N. Wang, Y. Zhang, W. Shen, X. Gao, and T. Li, "Solvent injection-lyophilization of tert-butyl alcohol/water cosolvent systems for the preparation of drug-loaded solid lipid nanoparticles," Colloids and Surfaces B, vol. 79, no. 1, pp. 254-261, 2010.

[102] C. Olbrich, N. Schöler, K. Tabatt, O. Kayser, and R. H. Müller, "Cytotoxicity studies of Dynasan 114 solid lipid nanoparticles (SLN) on RAW 264.7 macrophages-impact of phagocytosis on viability and cytokine production," Journal of Pharmacy and Pharmacology, vol. 56, no. 7, pp. 883-891, 2004.

[103] Z. Rahman, A. S. Zidan, and M. A. Khan, "Non-destructive methods of characterization of risperidone solid lipid nanoparticles," European Journal of Pharmaceutics and Biopharmaceutics, vol. 76, no. 1, pp. 127-137, 2010.

[104] S. Chakraborty, D. Shukla, P. R. Vuddanda, B. Mishra, and S. Singh, "Utilization of adsorption technique in the development of oral delivery system of lipid based nanoparticles," Colloids and Surfaces B, vol. 81, no. 2, pp. 563-569, 2010.

[105] D. Pandita, A. Ahuja, T. Velpandian, V. Lather, T. Dutta, and R. K. Khar, "Characterization and in vitro assessment of paclitaxel loaded lipid nanoparticles formulated using modified solvent injection technique," Pharmazie, vol. 64, no. 5, pp. 301-310, 2009.

[106] R. Li, J. S. Eun, and M.-K. Lee, "Pharmacokinetics and biodistribution of paclitaxel loaded in pegylated solid lipid nanoparticles after intravenous administration," Archives of Pharmacal Research, vol. 34, no. 2, pp. 331-337, 2011.

[107] R. Mauludin, R. H. Muller, and C. M. Keck, "Development of an oral rutin nanocrystal formulation," International Journal of Pharmaceutics, vol. 370, no. 1-2, pp. 202-209, 2009.

[108] S. Xie, L. Zhu, Z. Dong et al., "Preparation, characterization and pharmacokinetics of enrofloxacin-loaded solid lipid nanoparticles: influences of fatty acids," Colloids and Surfaces $B$, vol. 83, no. 2, pp. 382-387, 2011.

[109] S. Chakraborty, D. Shukla, B. Mishra, and S. Singh, "Lipidan emerging platform for oral delivery of drugs with poor bioavailability," European Journal of Pharmaceutics and Biopharmaceutics, vol. 73, no. 1, pp. 1-15, 2009.

[110] Y. Luo, D. Chen, L. Ren, X. Zhao, and J. Qin, "Solid lipid nanoparticles for enhancing vinpocetine's oral bioavailability," Journal of Controlled Release, vol. 114, no. 1, pp. 53-59, 2006.

[111] J. K. Vasir, K. Tambwekar, and S. Garg, "Bioadhesive microspheres as a controlled drug delivery system," International Journal of Pharmaceutics, vol. 255, no. 1-2, pp. 13-32, 2003.

[112] S. Xie, B. Pan, M. Wang et al., "Formulation, characterization and pharmacokinetics of praziquantel-loaded hydrogenated castor oil solid lipid nanoparticles," Nanomedicine, vol. 5, no. 5, pp. 693-701, 2010.

[113] C. Han, C. M. Qi, B. K. Zhao et al., "Hydrogenated castor oil nanoparticles as carriers for the subcutaneous administration of tilmicosin: in vitro and in vivo studies," Journal of Veterinary Pharmacology and Therapeutics, vol. 32, no. 2, pp. 116-123, 2009.

[114] D. Pandita, A. Ahuja, V. Lather et al., "Development of lipidbased nanoparticles for enhancing the oral bioavailability of paclitaxel," AAPS PharmSciTech, vol. 12, no. 2, pp. 712-722, 2011.

[115] H. Yuan, J. Chen, Y. Z. Du, F. Q. Hu, S. Zeng, and H. L. Zhao, "Studies on oral absorption of stearic acid SLN by a novel fluorometric method," Colloids and Surfaces B, vol. 58, no. 2, pp. 157-164, 2007.

[116] T. G. Smijs and J. A. Bouwstra, "Focus on skin as a possible port of entry for solid nanoparticles and the toxicological impact," Journal of Biomedical Nanotechnology, vol. 6, pp. 469-484, 2010.

[117] H. L. Karlsson, "The comet assay in nanotoxicology research," Analytical and Bioanalytical Chemistry, vol. 398, no. 2, pp. 651-666, 2010.

[118] C. F. Jones and D. W. Grainger, "In vitro assessments of nanomaterial toxicity," Advanced Drug Delivery Reviews, vol. 61, no. 6, pp. 438-456, 2009.

[119] A. C. Silva, E. González-Mira, M. L. García et al., "Preparation, characterization and biocompatibility studies on risperidone-loaded solid lipid nanoparticles (SLN): high pressure homogenization versus ultrasound," Colloids and Surfaces B, vol. 86, no. 1, pp. 158-165, 2011.

[120] R. H. Müller, D. Rühl, S. Runge, K. Schulze-Forster, and W. Mehnert, "Cytotoxicity of solid lipid nanoparticles as a function of the lipid matrix and the surfactant," Pharmaceutical Research, vol. 14, no. 4, pp. 458-462, 1997.

[121] M. Nassimi, C. Schleh, H. D. Lauenstein et al., "A toxicological evaluation of inhaled solid lipid nanoparticles used as a potential drug delivery system for the lung," European Journal of Pharmaceutics and Biopharmaceutics, vol. 75, no. 2, pp. 107-116, 2010.

[122] V. Meunier, M. Bourrie, Y. Berger, and G. Fabre, "The human intestinal epithelial cell line Caco-2; pharmacological and pharmacokinetic applications," Cell Biology and Toxicology, vol. 11, no. 3-4, pp. 187-194, 1995.

[123] V. Mathur, Y. Satrawala, M. S. Rajput, P. Kumar, P. Shrivastava, and A. Vishvkarma, "Solid lipid nanoparticles in cancer therapy," International Journal of Drug Delivery, no. 2, pp. 192-199, 2010.

[124] M. Harms and C. C. Müller-Goymann, "Solid lipid nanoparticles for drug delivery," Journal of Drug Delivery Science and Technology, vol. 1, no. 21, 2011.

[125] U. H. Cegla, "Long-term therapy over 2 years with ambroxol (Mucosolvan) retard capsules in patients with chronic bronchitis. Results of a double-blind study of 180 patients," Praxis und Klinik der Pneumologie, vol. 42, no. 9, pp. 715-721, 1988.

[126] P. Speiser, Lipid nanopellets as carrier system for drugs for oral administration, 1990.

[127] M. Üner and G. Yener, "Importance of solid lipid nanoparticles (SLN) in various administration routes and future perspectives," International Journal of Nanomedicine, vol. 3, no. 2, 2007.

[128] W. Wei, S. J. Shi, J. Liu et al., "Lipid nanoparticles loaded with 10-hydroxycamptothecin-phospholipid complex developed for the treatment of hepatoma in clinical application," Journal of Drug Targeting, vol. 18, no. 7, pp. 557-566, 2010.

[129] B. Sarmento, S. Martins, D. Ferreira, and E. B. Souto, "Oral insulin delivery by means of solid lipid nanoparticles," International Journal of Nanomedicine, vol. 2, no. 4, pp. 743749, 2007. 

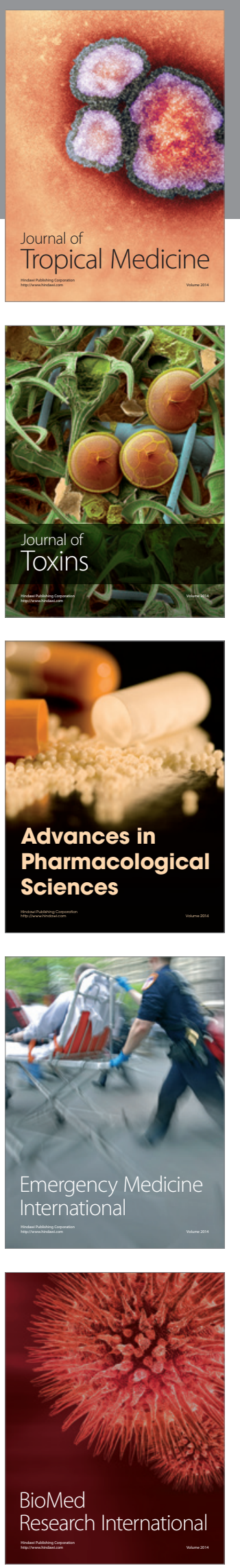
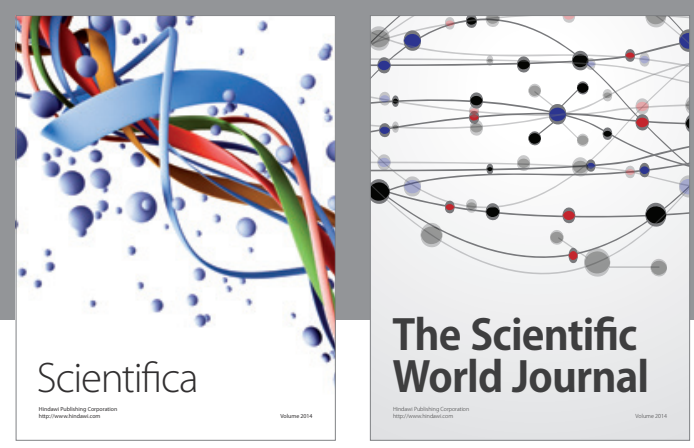

The Scientific World Journal
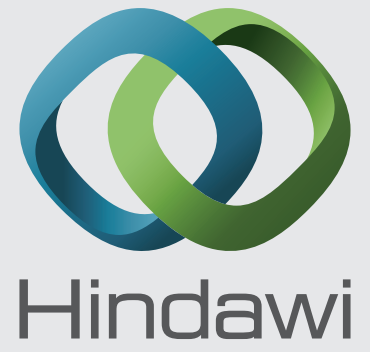

Submit your manuscripts at

http://www.hindawi.com
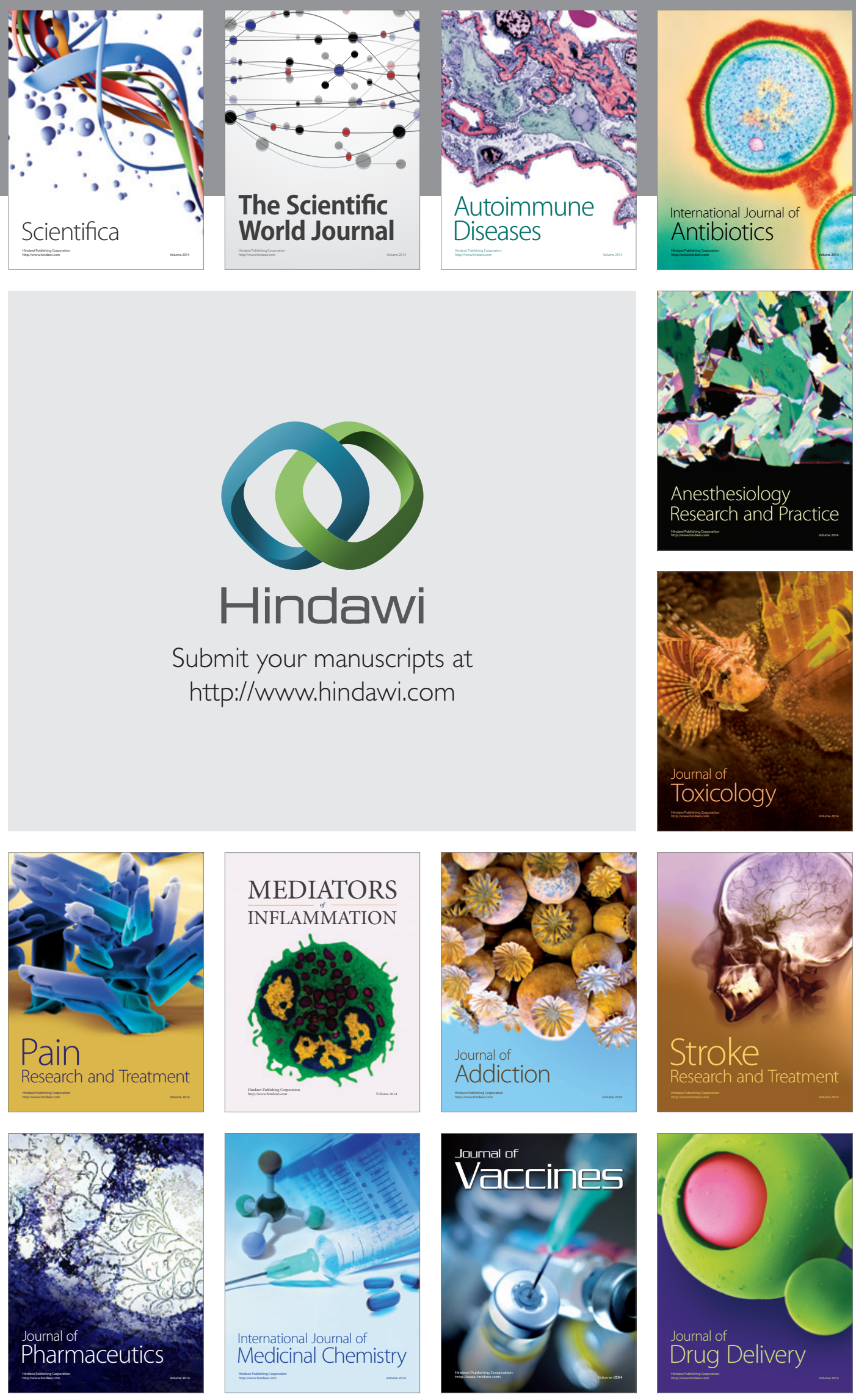